\title{
Study on Constraint on the Readiness of Using Building Information Modelling (BIM) for Construction Project in Indonesia
}

\author{
Hery Agustian $^{1}$ and Sarwono Hardjomuljadi ${ }^{2}$ \\ ${ }^{1-2}$ Department of Civil Engineering \\ Mercu Buana University \\ Jakarta, Indonesia
}

\begin{abstract}
Building Information Modeling (BIM) is a paradigm shift that has many benefits, not only for those engaged in building construction but also for the wider community. The benefits of BIM include a more integrated design and construction process, resulting in better quality buildings, lower costs and lower duration. However, to master BIM in Indonesia, many factors have not been achieved. This study uses the Analytical Hierarchy Process (AHP) to get the constraint factors for the readiness of using BIM in Indonesia which consists of 3 criteria in which there are 19 sub-criteria. There are 5 (five) experts who have competence in the field of building Information Modeling with at least 10 years of experience carrying out the assessment. The results of expert research show that the most dominant factors on the readiness of using BIM are Maturity in Understanding BIM.
\end{abstract}

Keywords: Building Information Modelling (BIM), Analytical Hierarchy Process (AHP), Construction Projects.

\section{INTRODUCTION}

Based on the Regulation of the Ministry of Public Works and Housing of the Republic of Indonesia Number 22 / PRT / M / 2018 about the Construction of State Buildings, the contents of the regulation listed in attachment IV page 196 activities and duties of construction service providers, point 13 "The use of Building Information Modeling" must be applied for unsimple State Buildings with the area's criteria is above $2000 \mathrm{~m} 2$ (two thousand square meters) and above 2 (two) floors. The output of the planning is the design result of using BIM for architectural drawings, structural drawings, utility drawings, landscape drawings, detailed volume of work implementation and budget plans. However, to achieve this ideal process, in Indonesia we cannot be sure when the ideal process will occur. So the company needs preparation and makes the BIM-based work system (Pilot study, 2015).

\section{ANALYTIC HIERARCHY PROCESS (AHP)}

AHP is a flexible model that allows us to carry out analysis and make decisions by combining considerations and personal values logically, it can build a new scale to measure the properties that have occurred [1]. AHP is a process in decision-making by using pairwise comparisons to explain the evaluation factors and weighting factors in multi-factor conditions [2]. The method of analysis is essential to identify the variables that are relevant to the research results obtained in accordance with the purpose. As an input to this analysis is the data information on the results of the questionnaire respondents. AHP is a method used to solve complex problems and are not structured into groups, by organizing groups into hierarchies, then enter a numerical value instead of human perception of relative comparison. By the synthesis, it will be able to determine which elements should have the highest priority [3]

Table.1. Scale Comparison

\begin{tabular}{|c|l|l|}
\hline $\begin{array}{c}\text { Intensity } \\
\text { interest }\end{array}$ & \multicolumn{1}{|c|}{ Information } & \multicolumn{1}{|c|}{ Explanation } \\
\hline 1 & Both elements are equally important & The two elements have the same effect major goal \\
\hline 3 & $\begin{array}{l}\text { Elements that one bit of important } \\
\text { than other elements }\end{array}$ & $\begin{array}{l}\text { Experience and judgment slightly favor one element by } \\
\text { comparison with other elements }\end{array}$ \\
\hline 5 & $\begin{array}{l}\text { Elements which one is more important } \\
\text { than other elements }\end{array}$ & $\begin{array}{l}\text { Experience and very strong valuation support one element than } \\
\text { other elements }\end{array}$ \\
\hline 7 & $\begin{array}{l}\text { One obvious element is the absolute } \\
\text { important of other elements }\end{array}$ & One powerful element supported and looked dominant in practice \\
\hline
\end{tabular}




\begin{tabular}{|c|l|l|}
\hline 9 & $\begin{array}{l}\text { One absolutely essential element other } \\
\text { than the elements }\end{array}$ & $\begin{array}{l}\text { Evidence supporting elements that one has the highest possible } \\
\text { degree of confirmation strengthens compared to other elements. }\end{array}$ \\
\hline $2,4,6,8$ & $\begin{array}{l}\text { The values between these two values is given when there are two adjacent consideration compromise } \\
\text { between the two options }\end{array}$ \\
\hline
\end{tabular}

\section{BUILDING INFORMATION MODELLING (BIM)}

Building Information Modeling (BIM) is a paradigm shift that has many benefits, not only for those engaged in building construction but also for the wider community [4]. The benefits of BIM include a more integrated design and construction process, resulting in better quality buildings, lower costs and lower duration [5] BIM supports data exchange between software to speed up analysis cycle times and cut the process of entering data for errors transfer [6].

\section{RESEARCH OBJECTIVES}

The objectives of this research are:

a. Knowing the factors that affect the readiness of using BIM in construction projects in Indonesia.

b. Knowing the dominant factors that hinder the readiness of using BIM in construction projects in Indonesia.

\section{RESEARCH METHODS}

In this study, first, secondary data was collected to find the sub-variables and indicators that affect the research variables. It was carried out based on literature studies. Furthermore, based on secondary data, primary data was collected through a questionnaire survey to experts who have competence in the field of building Information Modeling with at least 10 years of experience. Flow in this study are:

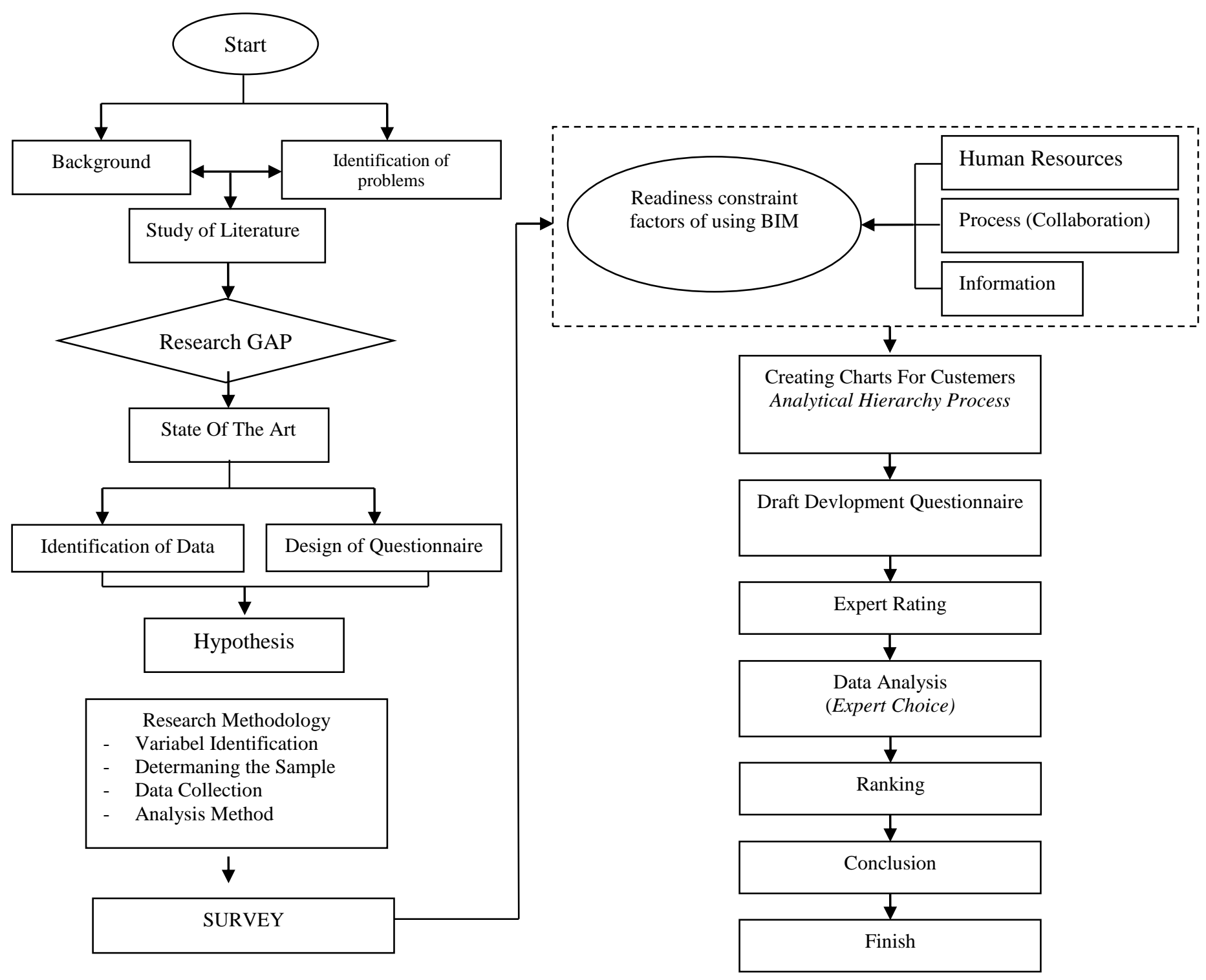

Figure 1. Flow Research 


\section{IDENTIFICATION OF VARIABLES}

AHP variables are arranged based on the level, namely the goal, then AHP model criteria is arranged based on the constraint factors of using BIM as presented in Table 2.

Table. 2 Variables of Research

\begin{tabular}{|c|c|}
\hline Criteria & Sub-criteria \\
\hline \multirow{4}{*}{ Human Resources } & Maturity and Understanding of BIM \\
\hline & BIM User Behavior \\
\hline & Team Trust \\
\hline & Problem of Collaboration \\
\hline \multirow{6}{*}{ Process (Collaboration) } & Lack of The Agreed Objectives \\
\hline & There is no clear procedure for BIM \\
\hline & Process of problematic information delivery \\
\hline & Different Team Skills \\
\hline & Share Problems in the Collaboration Process \\
\hline & Lack of The Supporting Resources (Software and Hardware) \\
\hline \multirow{9}{*}{ Information } & Ownership of Data \\
\hline & Intellectual Property \\
\hline & Interopobality \\
\hline & Large Volume of Data \\
\hline & Data Inconsistencies \\
\hline & Data Compability \\
\hline & Data Transport \\
\hline & Data Storage \\
\hline & Missing Data \\
\hline
\end{tabular}

\section{CONSISTENCY TEST}

In making decisions, it is important to know how good the consistency is because we don't want decisions based on importance with low consistency, check the hierarchy consistency, if the value is more than $10 \%$ then the assessment of the assessment data must be corrected, but if the consistency ratio is less or equal to 0,1 then the calculation results can be declared correct.

\section{GLOBAL PRIORITY RESULTS (EXPERT 1)}

The results of the overall pairwise comparison calculation of the criteria and sub-criteria for Human Resources, Process (Collaboration) and Information obtained Maturity and Understanding of BIM with a weight value of 0.357 is the first priority for readiness of using BIM, the second priority is ownership of data with a weight value of 0.119 , while the last priority is Lack of Supporting Resources (Software and Hardware) with a weight value of 0.004 . The global priority weight value for expert 1 is seen in Figure 2.

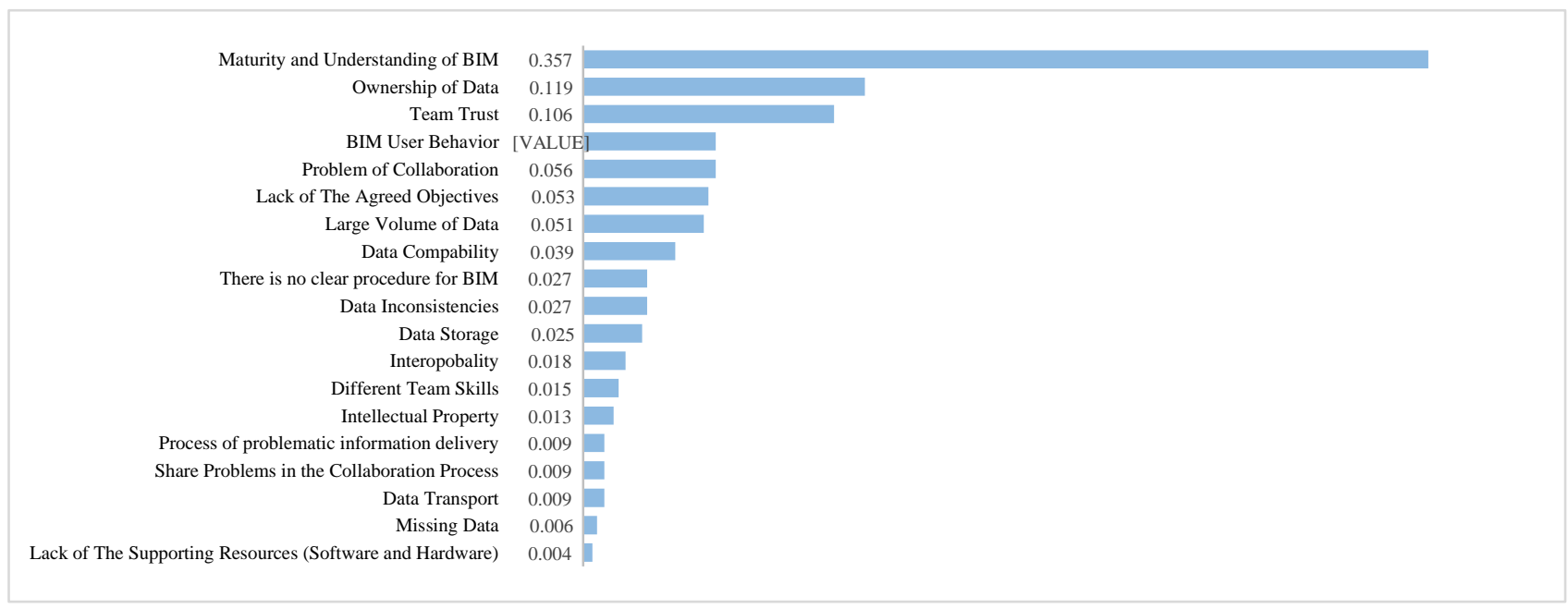

Figure 2. Weights Priority on the readiness Factors of using BIM in Construction Projects in Indonesia (Expert 1) Source: data processing by Expert Choice (Overall Inconsitency $=0,08$ ) 


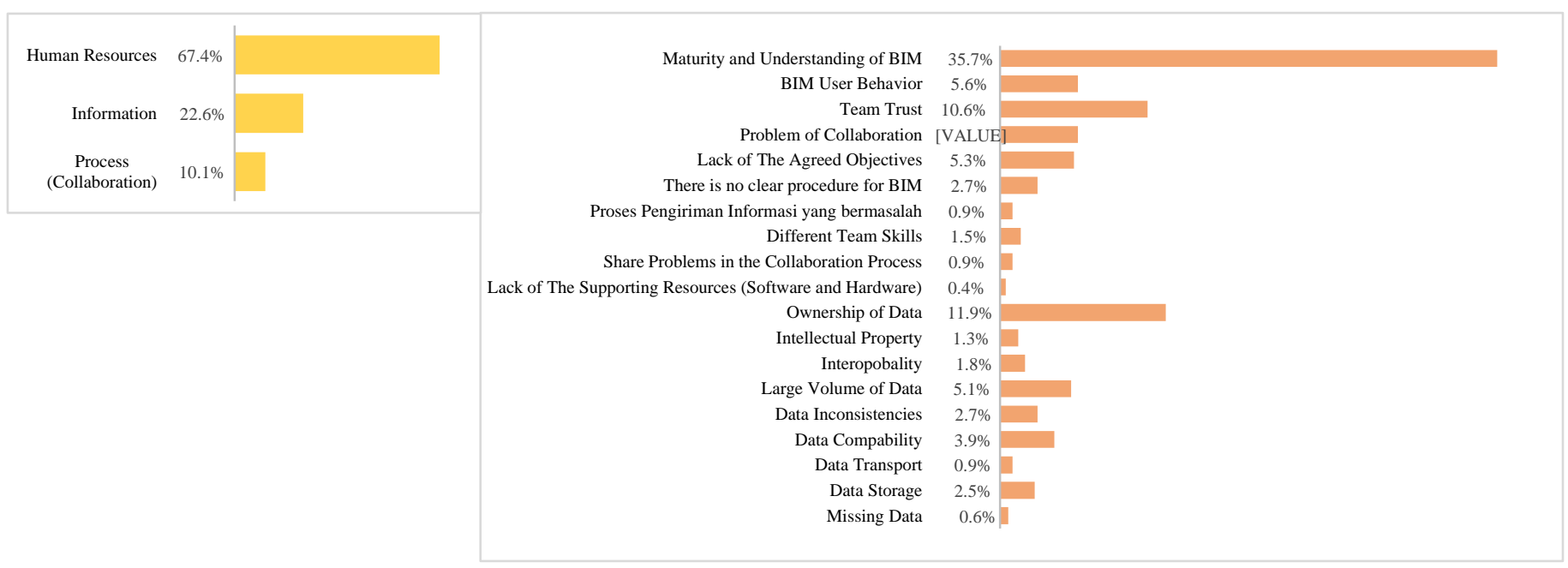

Figure 3. Dynamic Sensitivity Expert 1

Source : data processing by Expert Choice

\section{GLOBAL PRIORITY RESULTS (EXPERT 2)}

The results of the overall pairwise comparison calculation of the criteria and sub-criteria for Human Resources, Process (Collaboration) and Information obtained Maturity and Understanding of BIM with a weight value of 0.359 is the first priority for readiness of using BIM, the second priority is Lack of The agreed objectives with a weight value of 0.113 , while the last priority is Missing Data with a weight value of 0.004. The Global priority weight value for expert 2 is seen in Figure.4

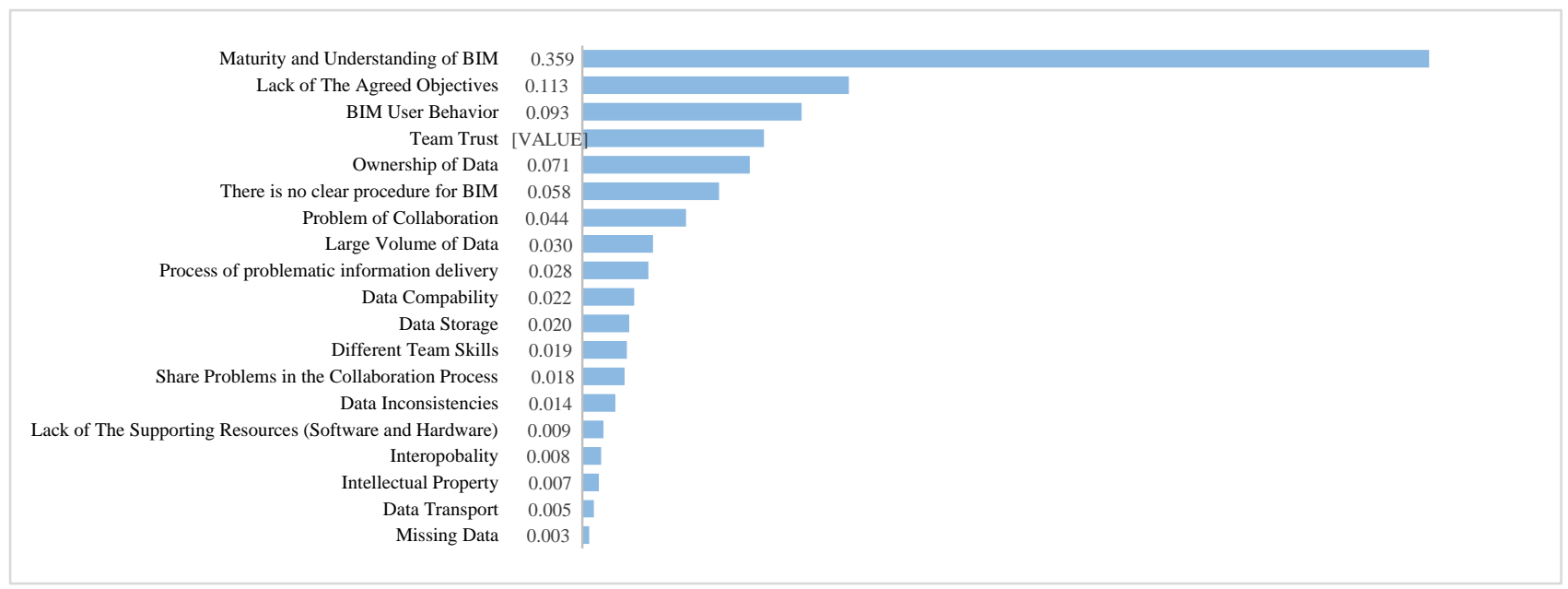

Figure 4. Weights Priority on the Readiness factors of using BIM in Construction Projects in Indonesia (Expert 2) Source: data processing by Expert Choice (Overall Inconsitency = 0,08)
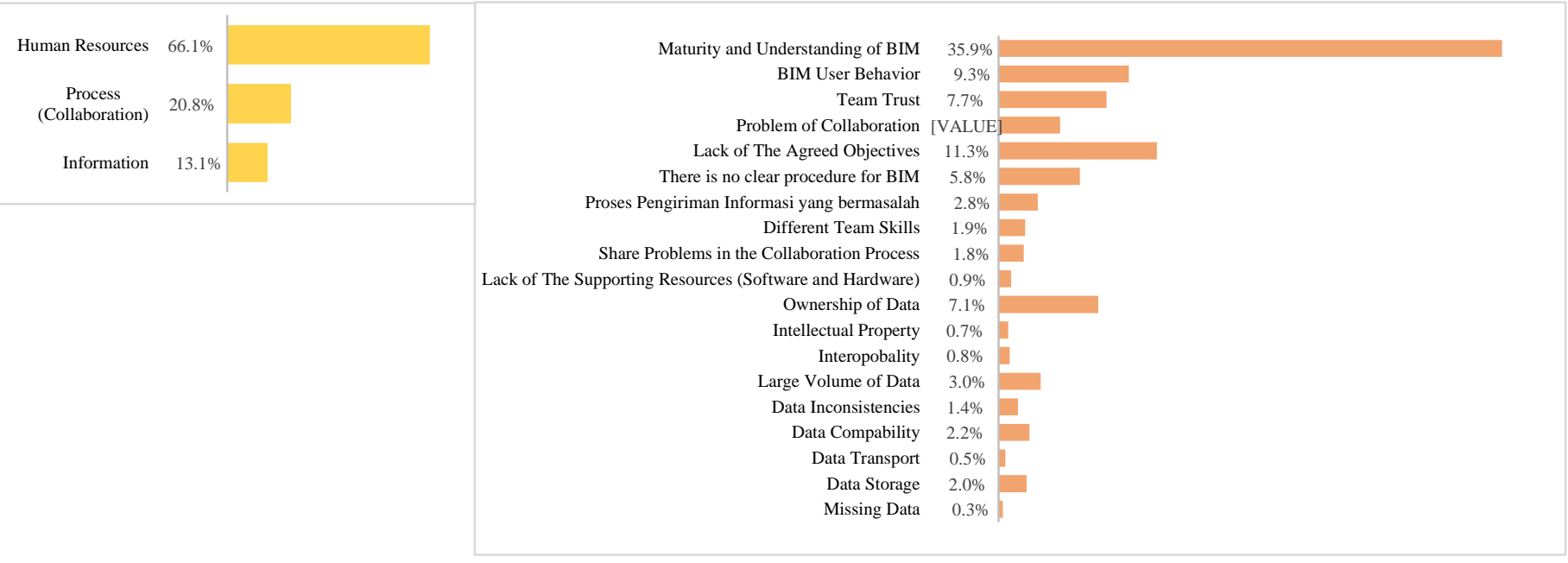

Figure 5. Dynamic Sensitivity (Expert 2)

Source: data processing by Expert Choice 


\section{GLOBAL PRIORITY RESULTS (EXPERT 3)}

The results of the overall pairwise comparison calculation of the criteria and sub-criteria for Human Resources, Process (Collaboration) and Information obtained Maturity and Understanding of BIM with a weight value of 0.376 is the first priority for readiness of using BIM, the second priority is Lack of Supporting Resources (Software and Hardware) with a weight value of 0.119 , while the last priority is Missing Data with a weight value of 0.004 . The Global priority weight value for expert 3 is seen in Figure 6.

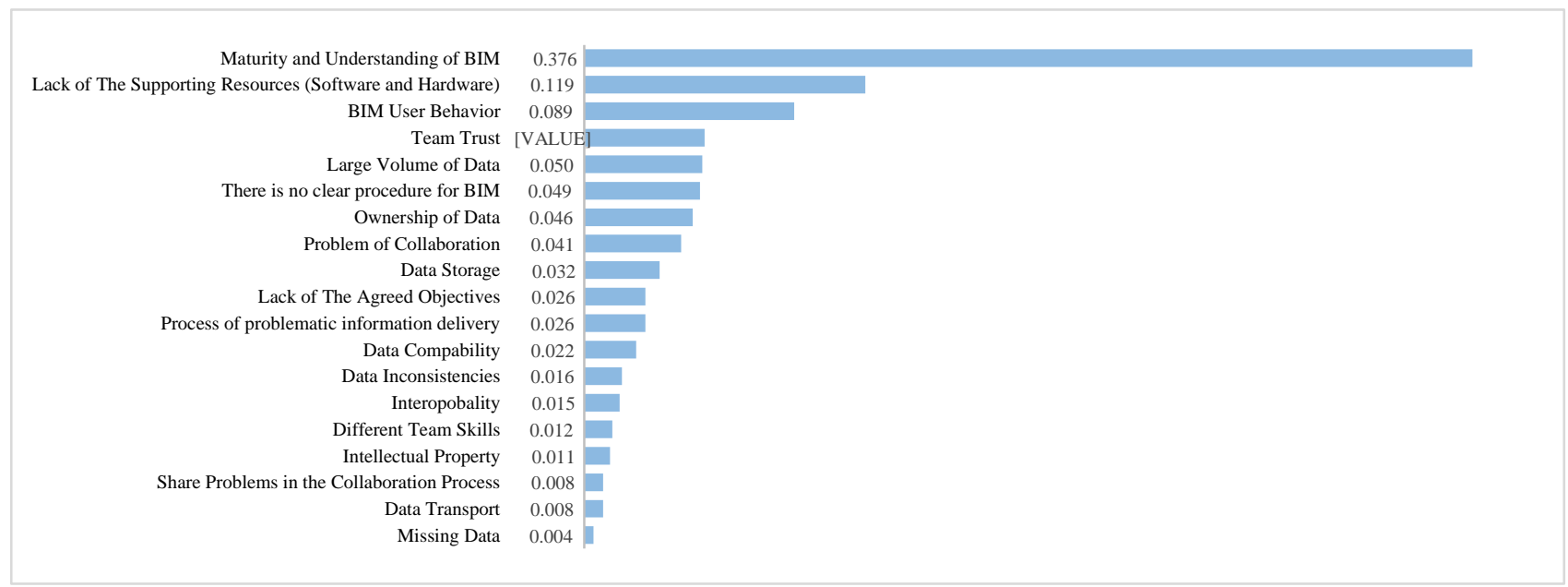

Figure 6. Weights Priority on the Readiness factors of using BIM in Construction Projects in Indonesia (Expert 3) Source: data processing by Expert Choice (Overall Inconsistency $=0.08$ )
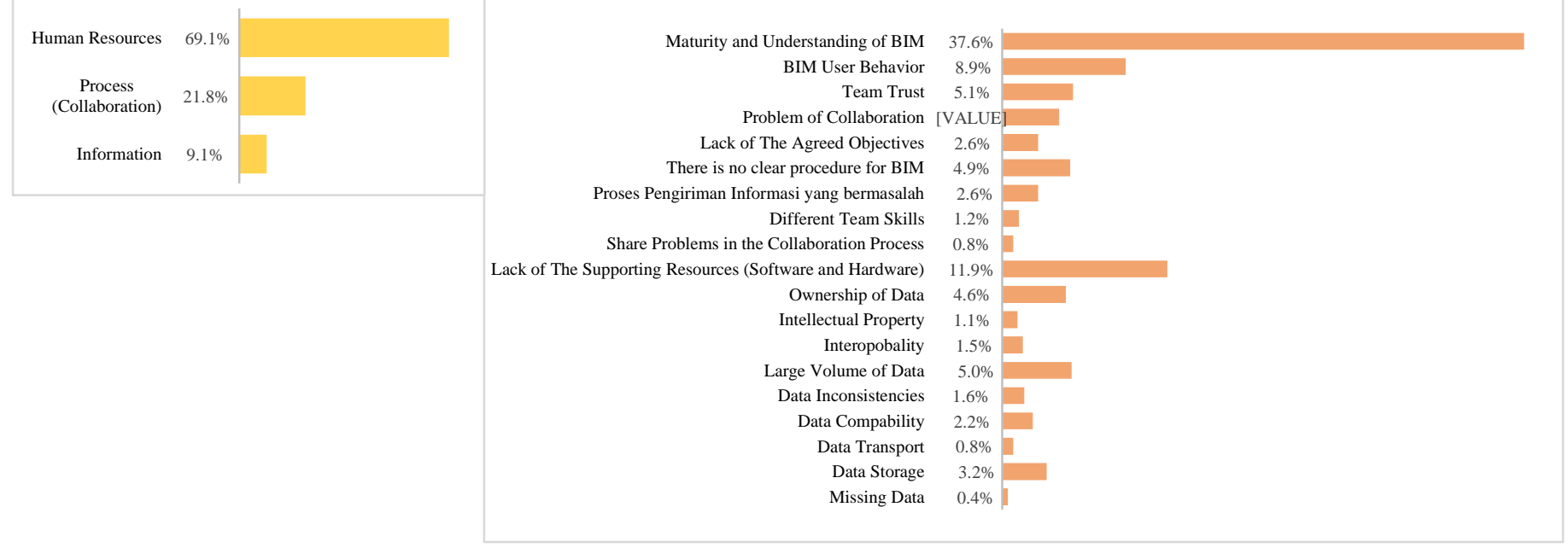

Figure 7. Dynamic Sensitivity (Expert 3)

Source: data processing by Expert Choice

\section{GLOBAL PRIORITY RESULTS (EXPERT 4)}

The results of the overall pairwise comparison calculation of the criteria and sub-criteria for Human Resources, Process (Collaboration) and Information obtained Maturity and Understanding of BIM with a weight value of 0.376 is the first priority for readiness of using BIM, the second priority is Lack of Supporting Resources (Software and Hardware) with a weight value of 0.119 , while the last priority is Missing Data with a weight value of 0.004 . The Global priority weight value for expert 4 is seen in Figure 8. 


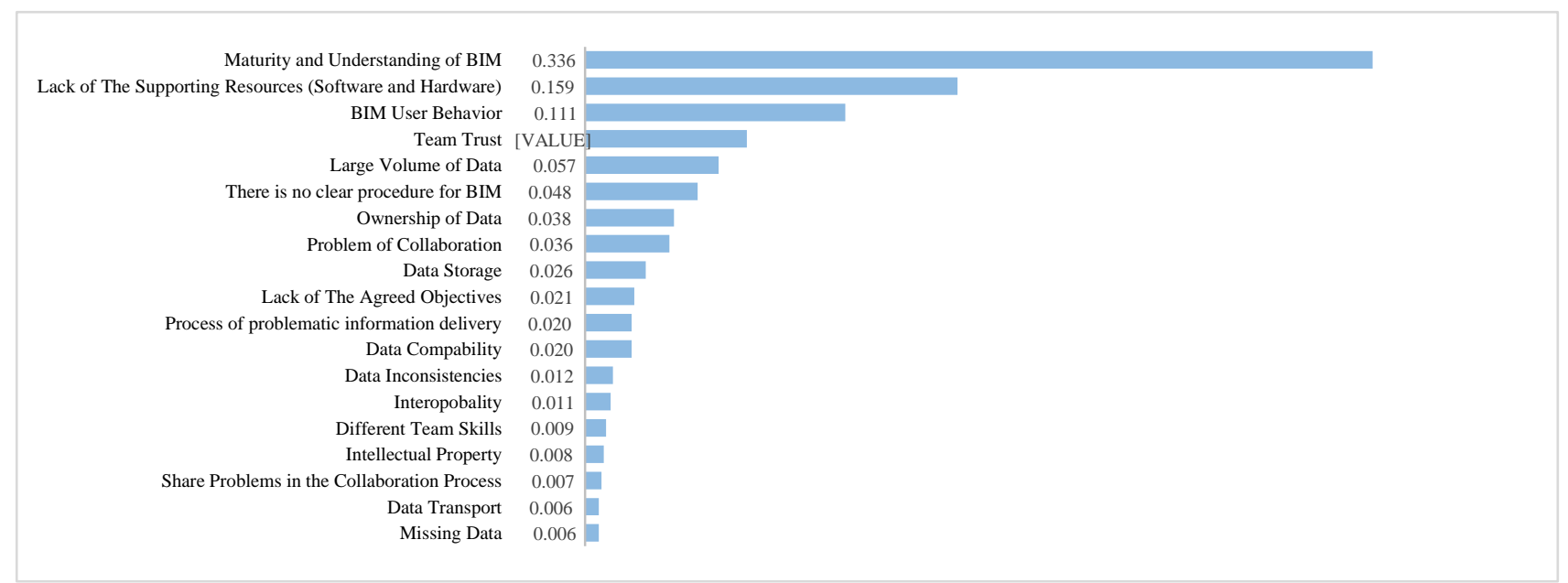

Figure 8. Weights Priority on the Readiness factors of using BIM in Construction Projects in Indonesia (Expert 4) Source: data processing by Expert Choice (Overall Inconsistency $=0,08$ )
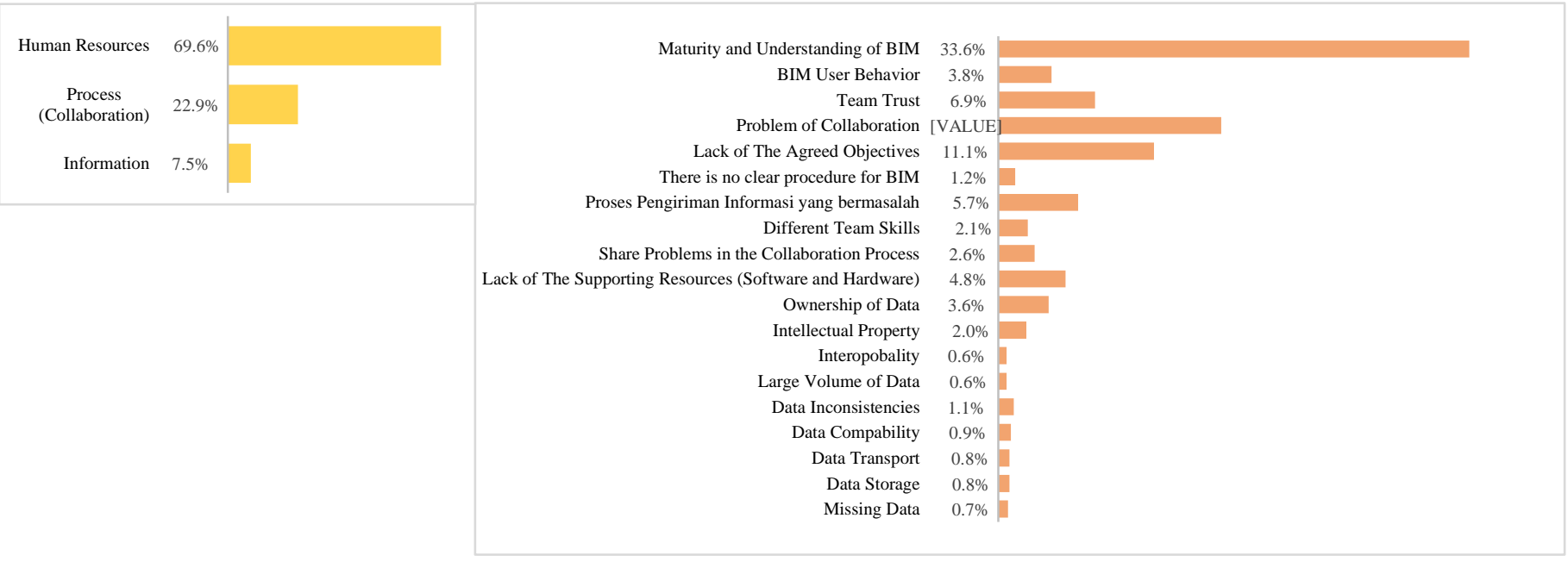

Figure 9. Dynamic Sensitivity (Expert 4)

Source: data processing by Expert Choice

\section{GLOBAL PRIORITY RESULTS (EXPERT 5)}

The results of the overall pairwise comparison calculation of the criteria and sub-criteria for Human Resources, Process (Collaboration) and Information obtained Maturity and Understanding of BIM with a weight value of 0,301 is the first priority for readiness of using BIM, the second priority is BIM User Behavior with a weight value of 0,128, while the last priority is Large Volume of Data with a weight value of 0,004. The Global priority weight value for expert 5 is seen in Figure 10.

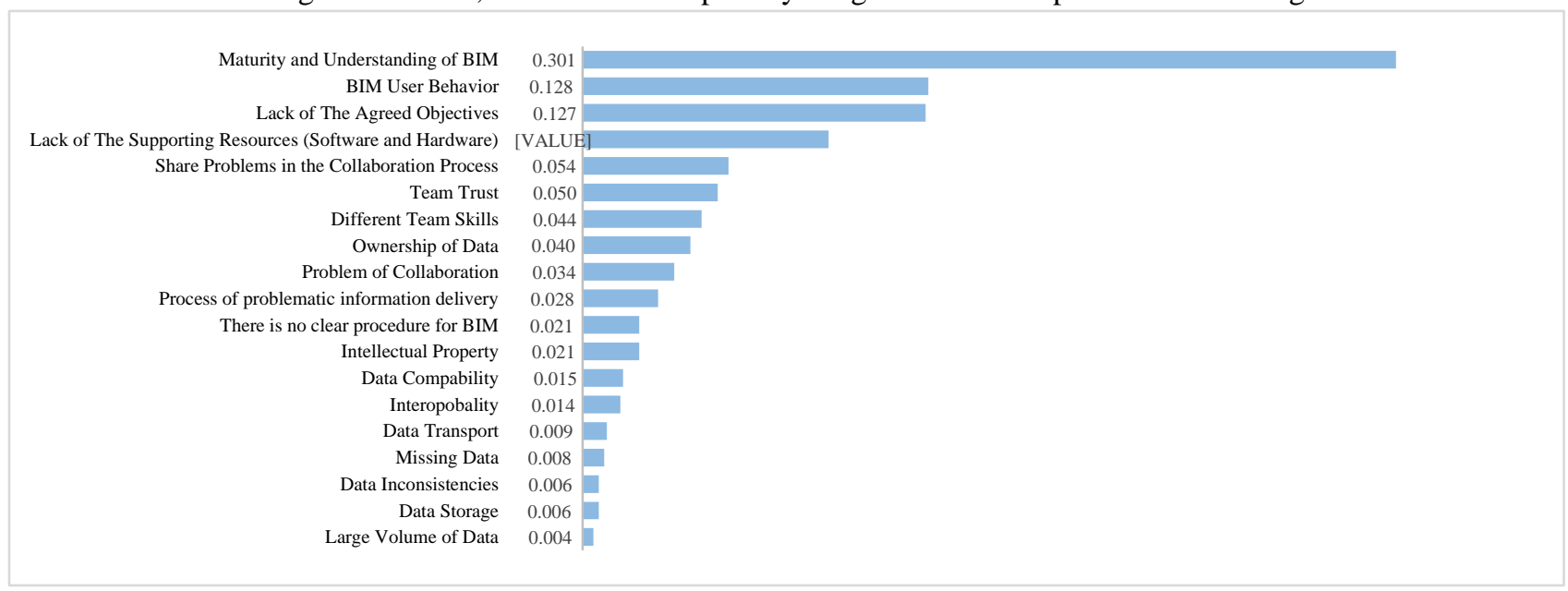

Figure 10. Weights Priority on the Readiness factors of using BIM in Construction Projects in Indonesia (Expert 5) Source: data processing by Expert Choice (Overall Inconsistency $=0,08$ ) 


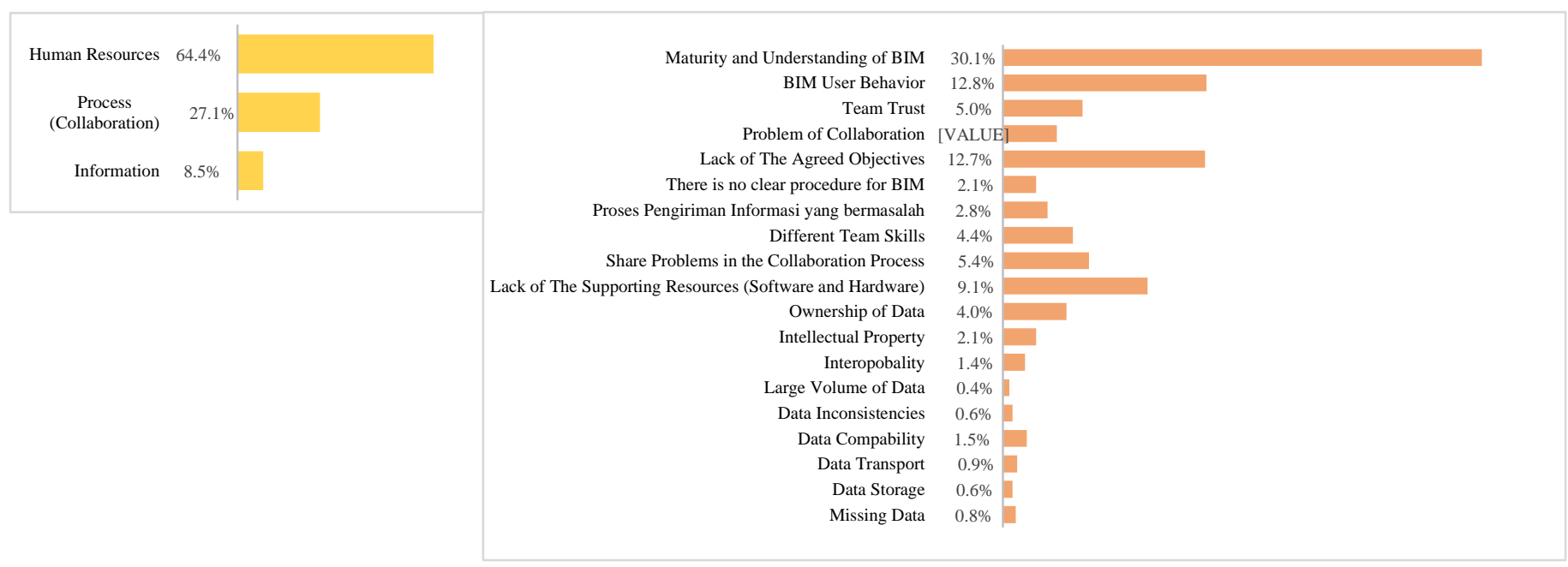

Figure 11. Dynamic Sensitivity (Expert 5) Source: data processing by Expert Choice

\section{CONCLUSIONS}

Based on the research results, it can be concluded that the constraints of using BIM in construction projects in Indonesia consist of 19 factors. According to the first expert, Maturity and Understanding of BIM with a weight value of 35.7\% is the first priority for readiness to use BIM, the second priority is ownership of data with a weight value of $11.9 \%$, while the last priority is Lack of Supporting Resources (Software and Hardware) with a weight value of $0.4 \%$. According to the second experts, Maturity and Understanding of BIM with a weight value of $35.9 \%$ is the first priority for readiness to use BIM, the second priority is Lack of Agreed Objectives with a weight value of $11.3 \%$ and the last priority is Missing Data with a weight value $0.4 \%$. According to the third experts, Maturity and Understanding of BIM with a weight value of $37.6 \%$ is the first priority for readiness of using BIM, the second priority is Lack of Supporting Resources (Software and Hardware) with a weight value of $11.9 \%$, while the last priority is Missing Data with a weight value of $0.4 \%$. According to the fourth experts, Maturity and understanding of BIM with a weighted value of $37.6 \%$ is the first priority for readiness to use BIM, the second priority is Lack of Supporting Resources (Software and Hardware) with a weight value of $11.9 \%$, while the last priority is Missing Data with a weight value of $0.4 \%$. According to te last experts, Maturity and Understanding of BIM with a weight value of $30.1 \%$ is the first priority for readiness to use BIM, the second priority is BIM User Behavior with a weight value of $12.8 \%$, while the last priority is Large Volume of Data with a weight value. $0.4 \%$. Based on the expert assessments, the most dominant constraint factor on the readiness of using BIM in construction projects in Indonesia, is the Maturity and Understanding of BIM.

\section{REFERENCES}

[1] Saaty T. (2008). Decision Making The Analytic Hierarchy Process, 1(83). https://doi.org/10.1504/IJSSCI.2008. 017590

[2] Saaty T. (2008). Relative Measurement and Its Generelization in Decision Making: Why Pairwise Comparisons are Central in Mathematics for the Measurement of Intangible Factors. Rev R Acad Cien, 102(2) 251-318. Retrieved from https://www.rac.es/fiecheros/doc/00576.PDF

[3] Santoso, D., \& Besral, A. M. (2018). Supplier Performance Assessment Using Analytical Hierarchy Process Method. Sinergi, 22(1), 37. https://doi.org/10.22441/sinergi.2018.1.007

[4] Eastman, C. M, C., Teicholz, P., Sacks, R., \& Liston, K. (2011). BIM Handbook: A Guide to Building Information Modelling for Owners Managers, Designers, Engineers and Contractors. Wiley, New York

[5] Sacks, R. Et al. (2018) BIM Handbook, https://doi.org/10.1002/9781119287568.

[6] Fischer, M., \& Kunz, J. (2004). The Scope and Role of Information Technology in Construction. Proceedings of JSCE 763 (2004) 1-8. 